Article

\title{
Assessing African Energy Transitions: Renewable Energy Policies, Energy Justice, and SDG 7
}

\author{
Franziska Müller ${ }^{1, *}$, Manuel Neumann ${ }^{2}$, Carsten Elsner ${ }^{2}$ and Simone Claar ${ }^{2}$ \\ ${ }^{1}$ Department of Social Sciences, University of Hamburg, 20146 Hamburg, Germany; \\ E-Mail: franziska.mueller@uni-hamburg.de \\ 2 Department of Social Sciences, University of Kassel, 34127 Kassel, Germany; E-Mails: mneumann@uni-kassel.de (M.N.), \\ carstenelsner@uni-kassel.de (C.E.), sclaar@uni-kassel.de (S.C.) \\ * Corresponding author
}

Submitted: 31 August 2020 | Accepted: 1 February 2021 | Published: 26 February 2021

\begin{abstract}
Renewable energy has made significant inroads in addressing growing energy demands on the African continent. However, progress towards SDG 7 is still limited and difficult to trace. Furthermore, the results-oriented rationale of the SDGs means that both policy change and the dimension of environmental justice are not covered properly. We argue that the energy justice concept may provide a powerful tool to offset looming trade-offs and enhance the co-benefits of SDG 7 within broader transition endeavours. In doing so, we assess African energy transition processes based on a comparative mapping of African renewable energy policies in 34 countries. We investigate the scope of policy frameworks in order to analyse their contribution to greater energy justice along different justice dimensions. We then identify four transition scenarios, which reflect the challenges of integrating the justice dimension into renewable energy policies. In comparing these scenarios, we argue that SDG 7 tracking needs to consider the justice dimension to arrive at a more holistic implementation that is in line with socio-ecological justice and takes account of people's energy needs.
\end{abstract}

\section{Keywords}

Africa; energy governance; energy justice; energy transition; policy analysis; renewable energy; Sustainable Development Goals

Issue

This article is part of the issue "The 2030 Agenda for Sustainable Development: Transformative Change through Sustainable Development Goals?" edited by Thomas Hickmann (University of Utrecht, The Netherlands), Markus Lederer (Technical University of Darmstadt, Germany), Jens Marquardt (Technical University of Darmstadt, Germany), Sandra Schwindenhammer (Justus Liebig University Giessen, Germany) and Sabine Weiland (Catholic University of Lille, France).

(C) 2021 by the authors; licensee Cogitatio (Lisbon, Portugal). This article is licensed under a Creative Commons Attribution 4.0 International License (CC BY).

\section{Introduction}

Renewable Energy (RE) has gained traction on the African continent. In the past 15 years, many African states have embarked on ambitious transition strategies and adopted RE legislation. Between 2006 and 2017, RE investments in Africa and the Middle East have multiplied from $\$ 1,2$ billion to $\$ 19$ billion (Climate Policy Initiative, 2019; Frankfurt School of Finance, 2017; Sovacool, Burke, Baker, Kotikalapudi, \& Wlokas, 2017, p. 19). Simultaneously, RE capacity on the African con- tinent has nearly doubled from $22.93 \mathrm{GW}$ in 2007 to $38.28 \mathrm{GW}$ in 2016 (Quitzow et al., 2016). Still, this pace does not seem to be sufficient, given sustained population growth, changing consumer habits as well as economic growth. Indeed, energy demand is projected to triple between 2015 and 2030, which underscores the need to combat energy poverty (Otieno, Taylor, Schroth, \& Franz, 2016). However, Africa's transition processes have largely gone unnoticed by social science, and this is demonstrated by a lack of comparative studies (cf., as two exceptions, Otieno et al., 2016; Quitzow et al., 2016) 
and by an epistemic and institutional mismatch with respect to the political sphere of energy transitions. This manifests specifically in SDG 7. While it measures energy access respectively energy poverty (affecting $53 \%$ of Africa's population, according to United Nations, 2020a, p. 10), documented by indicators which centre in on access to electricity (7.1.1) or access to renewables (7.2.1), it does not sufficiently pay attention to energy justice and misses out on promising RE policies and policy change. Indeed, a recent piece (Gellers \& Cheatham, 2019 , pp. 291-292) points out that just over $50 \%$ of the SDG's 169 targets relate to environmental justice concerns, with $38 \%$ focusing solely on the capabilities dimension, which in essence translates to a narrowing down of justice concerns to the individual level. Energy justice could only be traced in $3 \%$ of the SDG targets.

This echoes a broader critique of indicatorbased development, culminating in a substantial criticism of the SDGs depoliticizing transformative change (Lepennies, 2015; Ziai, 2015, pp. 195-196) and corresponds with debates that advocate for integrating environmental justice to arrive at more substantial policy change (Sovacool, 2016; Sovacool \& Dworkin, 2015). More specifically though, this points to specific tradeoffs between SDG 7 and SDG 13, and also uncertainties regarding SDG 7's interaction with labour markets (Kroll, Warchold, \& Pradhan, 2019; Nilsson et al., 2018). Integrating the policy dimension and a clear focus on energy justice for instance into electrification schemes would lead to more impactful results by targeting development needs more directly, and by carving out transition scenarios that reflect people's energy needs (Tarekegne, 2020), rather than giving way to financialized RE projects centred on a 'return-on-investment.' Furthermore, this would allow addressing injustices that were caused particularly by large-scale RE projects, which, during their planning and implementation stages failed to tackle participatory, recognitional and distributive needs (Calzadilla \& Mauger, 2017). We, therefore, argue that linking SDG 7 and energy justice provides evidence on how political stability, good governance and energy transitions may correspond. More so, adding the justice dimension allows addressing co-benefits, trade-offs, and synergies between SDG 7 and other SDGs more systematically. Against this backdrop, our research seeks to broaden the understanding of green policy change that pays heed to energy justice criteria. Based on our findings, we will argue, that the energy justice concept may provide a powerful tool to offset looming trade-offs and enhance co-benefits of SDG 7 within broader transition endeavours.

To close this research gap, this article assesses African energy transition processes in light of the debates on a 'just transition' and on 'energy justice' (Jenkins, McCauley, Heffron, Stephan, \& Rehner, 2016; Kern \& Markard, 2016; Newell \& Mulvaney, 2013; Swilling \& Annecke, 2012). Based on a previous comparative mapping of African RE policies in 34 countries (see, also for the full list of countries covered, Müller, Claar, Neumann, \& Elsner, 2020) we investigate the scope of policy frameworks and their contribution to greater energy justice. Our findings zoom in on a group of states, which have developed outstanding policy frameworks that may contribute to greater energy justice and thereby also to SDG 7: South Africa, Rwanda, and Mauritius. A nine-field matrix gives account of the various transition scenarios African states are currently charting out. Overall, we identified four transition scenarios which reflect the challenges for integrating the justice dimension into RE policies. Comparing these scenarios, we argue that SDG 7 tracking needs to consider the justice dimension to arrive at a more holistic implementation that is in line with socio-ecological justice and considers the political dimension of energy transition processes, rather than focusing on depoliticized indicators.

\section{Energy Justice in the Global South: Localizing the Justice Dimension in Energy Transition Policies}

Whether in industrialised or developing countries, energy transitions have become part of a universalized agenda towards sustainable development. Still, challenges such as technology transfer, job creation, grid integration or centre/periphery divides need to be addressed to develop viable scenarios also in the global South. Recently, the debate on 'energy justice' has concentrated on precisely these aspects. Drawing on earlier debates on environmental justice and environmental racism (Bullard, 2005; Bullard, Johnson, \& Wright, 1997), energy justice underscores the need to consider social questions referring for instance to access, affordability, distribution or people's needs. These are inherent to energy politics, particularly when combatting energy poverty. Based on liberal justice theory, namely the works of Sen (2009), Rawls (1971/1991), and Fraser (1999), we follow in the route of Jenkins and her co-authors in understanding energy justice as a threefold concept that combines distributive, recognitional, and procedural justice (Jenkins et al., 2016; Sovacool \& Dworkin, 2015). Distributive justice refers to the distributional effects of transition processes, that is, affordability of RE and access to RE. Recognitional justice asks whether transition strategies pay sufficient attention to energy poverty by addressing the needs of vulnerable groups. Procedural justice considers the democratic dimension, especially questions of participation and political articulation. Paying particular respect to social justice concerns, the concept provides a valuable analytical framework for assessing the course and content of energy transitions and has, consequently, found broad reception in the social sciences, including energy transitions in the Global South (Newell \& Mulvaney, 2013; Swilling \& Annecke, 2012).

Besides these applications, the concept has witnessed certain conceptual evolution, including a more nuanced understanding of justice. Heffron and McCauley 
(2017) expand the energy justice concept with restorative justice. With regards to energy, the concept forces decision-makers to engage with injustices caused by energy projects and rectify them. The cost of rectification may even prohibit the energy activity from being proposed in the first place, thus adding an essential element to the lifecycle of energy project implementation.

Brato, Baptista, Kirshner, Smith, and Alves (2018) and Barthel (2019) point out that the energy justice concept needs to pay additional attention to postcolonial realities, that is, the extent to which recent transition processes mirror colonial power structures in epistemological (access to transformation knowledge) or material terms (access to technology; Brato et al., 2018, p. 646). Sovacool et al. (2017) assess the liberal-cosmopolitan norm set which builds the ontological basis for most energy justice concepts, and detect Eurocentric notions, when referring to agency, political participation, and individual justice. They seek to pluralize, localize, and provincialize energy justice by linking the concept to norms stemming from Southern cosmovisions, such as ubuntu. Also, Sovacool et al. (2017) underscore the need to discuss co-benefits, but also trade-offs that go hand in hand with integrating energy justice into policy frameworks. This last point is of immense importance especially with reference to SDG 7, the design of RE policies, and to the co-benefits a more systemic mainstreaming of energy justice would entail.

While we can witness the expansion of energy justice as a conceptual framework, comparative perspectives have been a major missing piece in the puzzle, as demonstrated by a bibliometric analysis on energy justice scholarship in developing countries (Lacey-Barnacle, Robison, \& Foulds, 2020, pp. 125-130). This, however, is needed to gain stronger evidence on the course of transitions and their awareness for the justice dimension in relation to SDG 7. We particularly see the need to deepen the debate on co-benefits and trade-offs between SDG 7 and other SDGs, such as SDG 8 and SDG 13, and argue that a greater focus on energy justice and justice-related RE policies will significantly support these entanglements. First evidence by Calzadilla and Mauger (2017) explored the connection between energy justice and RE policies for four RE projects. They call for more holistic approaches towards fair and equitable energy access (see also Samarakoon, 2019). While we have already provided a mapping of RE policy frameworks and actors' coalitions in 34 African states elsewhere (Müller et al., 2020), we see the need to sharpen this view by coining certain transition scenarios and assess their potentials for greater energy justice and for realizing SDG 7. Only by leaving room for re-politicization, through the concept of energy justice, can transition endeavours create the necessary domestic buy-in and reach the envisioned impact of equitably improving access to energy. Based on our previous findings, a meta-analysis of our data identifies pertinent clusters of states undergoing RE transitions and provides several best practice examples.

\section{Mapping African Energy Transition Policies: Methodological Considerations}

Environmental policy analysis explores how policies address environmental concerns and govern political change. Typically, this subfield of political science and environmental governance explores certain policy networks and advocacy coalitions (Hermans, 2008; Weible \& Sabatier, 2005), political articulations (Fischer \& Forester, 1993; Hajer \& Veersteg, 2005; Hajer \& Wagenaar, 2003) or centres on policy impact assessments (Loomis \& Helfand, 2001). In a similar fashion, energy policy analysis assesses modes of energy governance, stakeholder activities, as well as content and impact of RE policies belonging to a wider policy mix (Rogge \& Reichardt, 2016). Analysing RE policies requires a methodology that allows mapping several features such as the political process leading to the adoption of certain policies, the objectives of a policy, a policy's comprehensiveness or coherence, and not least the wider field of external factors such as time scale or mode of governance (Rogge \& Reichardt, 2016, p. 1629).

Our sample encompasses all African countries that have adopted at least some RE legislation during the past two decades, which eventually resulted in 34 states. Our data was retrieved from publicly accessible databases on RE, namely the IEA/IRENA Joint Policies and Measures database (IEA \& IRENA, 2018), Global-Climatescope (2017), and the Regulatory Indicators for Sustainable Energy RISE (The World Bank Group, 2017). This was complemented by the REN 21's $(2020,2018)$ Renewables Global Status Report, the World Energy Outlooks, and IRENA's Renewables Readiness Assessments, as well as the individual RE legislation (AFRO_ENERGYPOL, 2020). For each country we summarized the RE policies in relation to their goals and content. Deductive coding of the respective policies allowed assessing the transformative potential and the normative quality. As our research interest is explicitly devoted to the policy content and the intended impact, we concentrated on two coding criteria: the transformative potential along a time scale and the normative quality of a given policy (Müller et al., 2020, pp. 2-4).

The transformative potential addresses the policy objectives and the interaction of various policy instruments within a policy framework. This dimension is defined by the scope of a policy as well as its scalability. It explores how a given policy contributes to policy change, drawing on a heuristic suggested by IRENA, IEA, and REN 21 (2018, pp. 15, 101-103), which is related to the Multi-Level Perspective framework of transformative change as initiated by Geels (2002), who differentiates between changes occurring on a niche level, on a regime level, and on a landscape level. Accordingly, and in line with IRENA's heuristics, we discern between three types of policies that operate on different levels within a transition process: direct policies, integrative policies, and enabling policies. Direct policies focus on concrete, 
yet less scalable interventions, such as tax reductions for solar cells. Integrative policies promote the integration of renewables by adapting or widening grid infrastructures, or by regulating heating standards, or biofuel blending standards. Enabling policies strive for transformative change, demonstrated by systemic strategies to raise awareness, promote education and training, nationwide energy access programmes, or green industrial policies (IRENA et al., 2018, p. 15).

The normative quality investigates whether policy frameworks contribute to greater energy justice, i.e., procedural, distributive, and recognitional dimensions of the energy justice framework (Jenkins et al., 2016). When assessing the normative quality, we reflected whether a given policy framework contributes to procedural justice, i.e., democratic and legitimate policy processes. To assess the degree of distributive justice, we analysed whether a nation's policy framework enhances energy access and its fair distribution, indicated by specific policies for energy access in rural areas or grid integration. Lastly, to assess the degree of recognitional energy justice, we evaluated whether a policy framework took into account the energy needs of particularly vulnerable groups (for instance people in remote regions, people affected by disabilities or chronic diseases, and not least mothers or children). This last aspect also reflects aims of the SDG 7 (access to affordable and clean energy; Müller et al., 2020, pp. 2-4). For coding the transformative potential, we referred to IRENA's heuristic and coded each RE policy as either direct, integrative, or enabling, in each case depending on the policy content and the intended objectives. Likewise, we coded each policy according to its contribution to distributive, recognitional, or procedural justice (see Supplementary File for details). Inter-coder reliability was guaranteed during the coding process, as each country coding was reviewed by another team member.

The mapping results provided first empirical insights into the roll-out of RE policies across the African continent (cf. Müller et al., 2020) and served as a basis for a meta-analysis of our data that builds on our previous findings, but further elaborates on the scope of policies and their contributions to different justice dimensions. This analytical step allowed identifying certain transition scenarios (Section 4.3) and yields more in-depth insights into the ways in which the form of government is related to the greater goal of energy justice and policy change. This is particularly important as the SDGs' understanding of sustainable development highlights a transformation of state, economy, and society.

\section{Results: African Energy Transition Scenarios}

While our mapping seconds general evidence that RE policies are on the rise, it also indicates that their dynamics and directions vary considerably. Overall, RE transitions in Africa lean towards comprehensive policy mixes that combine direct, enabling, and integrative policies (IRENA et al., 2018, p. 15; Müller et al., 2020). Referring to the justice dimension, our findings highlight that several policy frameworks pay attention to distributive and recognitional justice. However, our previous findings have not yet painted a clear picture of possible relations between the scope of RE policies, their contribution to greater energy justice, and the wider SDG context. We expect different entanglements, such as positive impacts, based on a tentative integration of justice into policy frameworks, but also negative effects, characterized by far-reaching policies that do not consider justice as relevant for green transformation. Both scenarios provide better insights into the current transition dynamics and their contribution for realizing SDG 7. Before presenting the results of our meta-analysis (Section 4.3), we briefly summarize the overall findings in Sections 4.1 and 4.2. For an in-depth discussion, Müller et al. (2020) give a detailed account of the policy mapping and our previous results.

\subsection{Steps towards Decarbonisation: Africa's Comprehensive RE Policy Frameworks}

Regarding the scope and direction of transition policies, we identified several states that introduced enabling policies promoting a systemic RE transition, often considering RE's cross-pollinating qualities as well as their socio-ecological and even educational dimension. This pattern was discernible in Algeria, Cabo Verde, Egypt, Ethiopia, Mauritius, Morocco, Rwanda, and South Africa (AFRO_ENERGYPOL, 2020). In comparing their different policy frameworks, we found that there was tendency towards adopting policies that aim at foreign direct investments, such as feedin tariffs, de-risking, and auction instruments. Feed-in tariffs have been put into place in Egypt, Ghana, Kenya, Mauritius, Namibia, Nigeria, Rwanda, Senegal, South Africa, Tanzania, Uganda, Zambia, Zimbabwe (AFRO_ENERGYPOL, 2020; Climate Policy Initiative, 2019; Quitzow et al., 2016; REN 21, 2020, pp. 231). De-risking refers to policies and consultancy activities that seek to render 'risky' markets attractive to foreign investors. Countries with de-risking programmes for the energy sector include Ghana, Namibia, Uganda, Ethiopia, and Zambia (Haag \& Müller, 2019; Müller \& Claar, in press; Waissbein, Glemarec, Bayraktar, \& Schmidt, 2013). Auction instruments, in turn, are based on a tendering process with competitive bidding and a scoring based on least-cost pricing. Additional scoring criteria such as local content requirements, employment of local personnel, and local shareholding may apply. So far, 25 countries on the African have adopted auction instruments, namely Zambia, Madagascar, Ethiopia, Rwanda, South Africa, Burkina Faso, Senegal, Kenya, Algeria, Mauritius, Cape Verde, Côte d'Ivoire, Egypt, Lesotho, Uganda, Malawi, Nigeria, the Gambia, Tunisia, Zimbabwe, Seychelles, Mali, Togo, Guinea Bissau and Morocco (AFRO_ENERGYPOL, 2020; Otieno et al., 2016; Quitzow et al., 2016; REN 21, 2018, pp. 19, 65-67, 2020, p. 72). 
The turn towards market-based instruments corresponds with a trend to adopt policy frameworks, which trust in the forces of the market. These policies aim at creating promising markets for RE investors by unbundling energy monopolies, enhancing transparency, and privatizing infrastructures (Müller et al., 2020, p. 5).

\subsection{Different Shades of Justice: Africa's Green Contributions to Energy Justice}

The justice dimension provides evidence whether a policy corresponds with distributive, procedural, and recognitional justice. Overall, we found that most policy frameworks in our sample showed at least some interest in distributive justice, i.e., considering access to and affordability of RE, evident, for instance, in rural electrification or cross-cutting issues such as educational and capacity-building programmes. Furthermore, many countries have adopted energy policies that consider the needs of particularly vulnerable populations, thus accounting for the dimension of recognitional justice. While combatting energy poverty is the overall goal of recognitional energy justice, this manifests in a broad range of policies which reach out to women, chronically ill and disabled people, and people affected by poverty. Examples include rural electrification, women's empowerment or tariff schemes geared towards the needs of vulnerable groups. However, some countries, such as Morocco and Tunisia, have strongly prioritized market- based solutions without adopting any justice-related RE legislation. This may be an early indicator of financialization, which prioritises 'bankability' of (renewable) energy projects (Baker, 2015; Gabor, 2019, 2020), ignores local industry needs and domestic participation in favour of de-risking transnational investment (Elsner, Neumann, Müller, \& Claar, in press), and downplays justice-related aspects (Müller et al., 2020, p. 6).

\subsection{Transition Dynamics: Best Practice and Challenges for a Just Transition towards SDG 7}

Do comprehensive policy frameworks also contribute to greater energy justice? Does attention for energy justice mean that a nation has equally progressed in adopting comprehensive policies? Both criteria do not necessarily correspond but may be intertwined in more complex ways. To provide evidence on the ongoing transition dynamics many states are facing, a nine-field matrix (Figure 1) displays the variance of the sample countries in relation to both their policy frameworks and their contribution to greater energy justice.

In our sample, several states stand out due to their highly detailed policy frameworks and the ways in which their policies consider energy justice criteria. Three states (1a) provide evidence of energy policies incorporating distributive and recognitional justice criteria. They foster a far-reaching energy transition, which is fully aware of RE's cross-cutting nature and

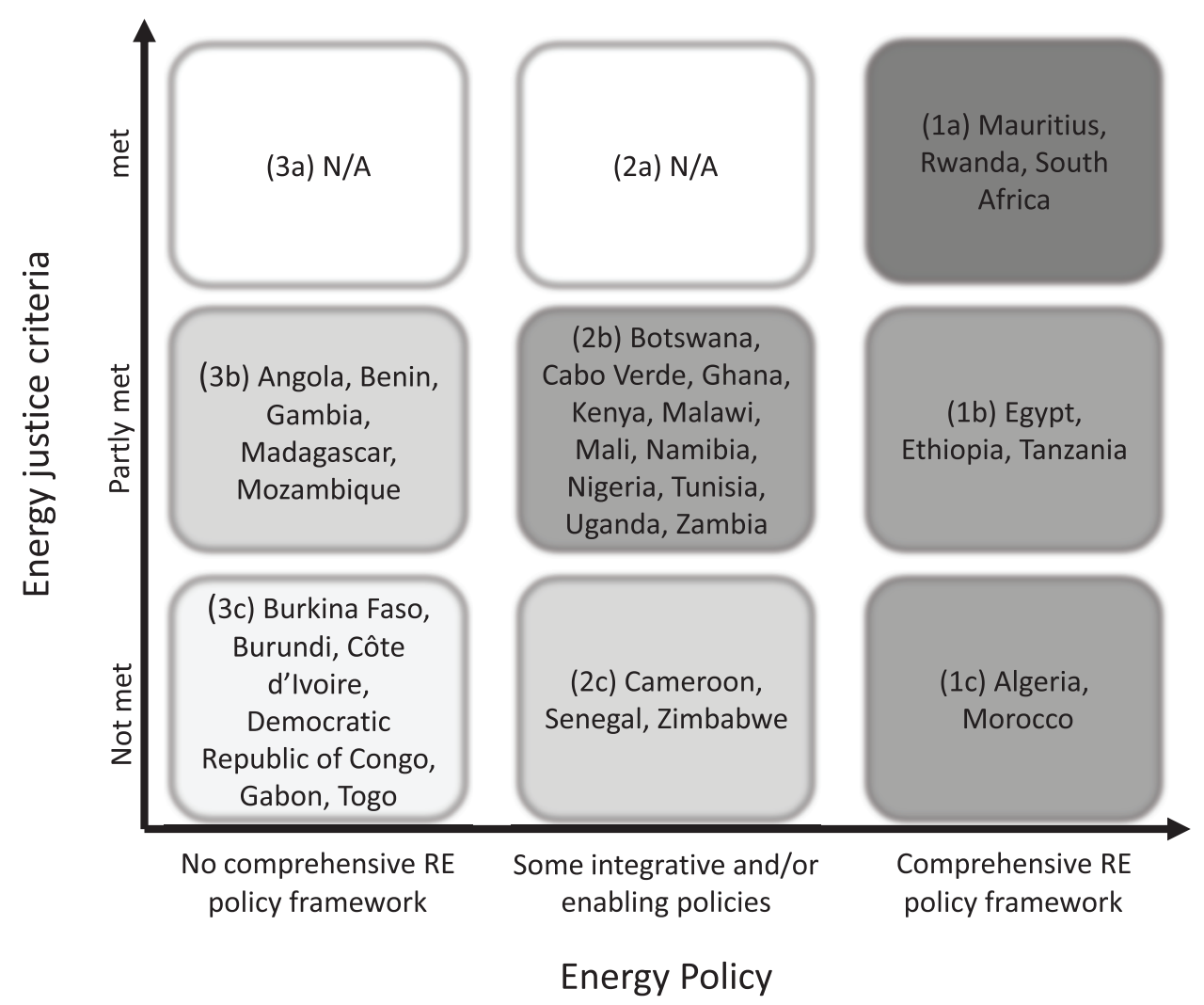

Figure 1. Energy transition frameworks. Source: Authors' compilation based on AFRO_ENERGYPOL (2020). 
its potentials for socio-ecological change. Mauritius' policy framework, namely its Long-Term Energy Strategy 2009-2025 (Republic of Mauritius, 2009), illustrates how this may be achieved in a country, dependent on fossil fuel imports on the one hand, but with huge potentials for expanding biomass from their sugarcane-based production regime that dates back to French and British colonial legacies on the other hand. The policy framework aims at a share of $35 \% \mathrm{RE}$, achieved by a feedin tariff and the development of the biomass sector, complemented by energy efficiency programmes and consumer incentives. The strategy underscores energy's justice dimension and affirms its cross-cutting qualities, indicated for instance by integrating gender-sensitive energy policies. These encompass capacity-building programmes, which seek to enhance energy access for women through microcredit systems and grassroots partnerships. Also, electronic payment systems consider the needs of women whose income flows are irregular. This kind of awareness for distributive and recognitional energy justice stands out among several policy frameworks and may serve as a significant cornerstone, especially for countering tendencies of promoting $R E$ as an elite technology for African middle-classes (Boamah \& Rothfuß, 2018). Another example is Rwanda's national energy strategy (Ministry of Infrastructure of Republic of Rwanda, 2009), a policy framework that encompasses several integrative and enabling policies that aim at increasing RE energy access and overcoming load shedding, which is now Rwanda's most pressing challenge due to a lack of investment in its outdated hydropower infrastructure. The strategy aims to tap both, geothermal energy and small hydro, and promotes energy efficiency schemes for the public and private sector. Green industrial policies are expressed in terms of energy audits for industries and information campaigns on good energy management practices. Furthermore, the extension of the transmission and distribution network is envisaged. The policy framework combines several small-scale and large-scale instruments, such as microfinance options, green funds, clean cooking programs and biofuel blending in the transport sector. Furthermore, the strategy recognizes RE's cross-cutting qualities through initiating capacity-building programs for increasing the proportion of women in RE technology.

Lastly, South Africa's energy policy mix combines direct, integrative, and enabling instruments that foster a green transition against the backdrop of a strong path dependency on fossil fuels inherited from the extractivist production regimes during British colonialism and the Apartheid regime (AFRO_ENERGYPOL, 2020). The Integrated Resource Plan aims at reducing fossils fuels to $30 \%$ and replacing them by renewables and a small amount of nuclear energy, thereby advocating for downgrading ESKOM, the nation's aging energy monopolist. Attention for recognitional justice is reflected by programmes for solar heating and basic energy support, such as the Free Basic Electricity programme. South
Africa's auction instrument REI4P added $6.3 \mathrm{GW}$ of RE to the national grid, with another $17.8 \mathrm{GW}$ to be projected up until 2030 (Baker, 2015; Müller \& Claar, in press). The program generated an estimated 42,300 job years. REI4P projects reflect distributional and recognitional justice in their socio-economic indicators. The individual projects have fostered education programmes and on-the-job training, and one third of the projects has a level of community ownership ranging between $20 \%$ and $40 \%$, despite the strong role of transnational capital (Claar, 2020, pp. 119-121; Müller \& Claar, in press).

In contrast to this group, we also find several least developed countries in (3c) which have neither been capable of adopting more than a few direct policies, nor included the justice dimension. In these cases, more advanced RE policies have not been put into place so far, due to weak state capacities, a lack of political agency, and, not least, insufficient donor activities driving RE policy innovation. Here, the Togolese case provides an account of the difficulties particularly least developed countries face when initiating a transition towards renewables. Togo has promising solar potential. But it heavily relies on traditional biomass and petroleum imports and $50 \%$ of the country's population are affected by energy poverty. The state has been incapable of developing a comprehensive energy policy framework (AFRO_ENERGYPOL, 2020). The existing policies only aim at implementing global commitments, such as the United Nations Framework Convention's on Climate Change intended nationally determined contributions. Promising initiatives have only recently started to tackle energy poverty through direct policies such as subsidies that cover solar off-grid electricity supply.

The quadrants (3b) and (2c) both refer to states still in the initial stages of a RE transition. Considering RE merely a welcome addition to their national energy mixes, they either lack proper attention to the justice dimension, or only adopted few direct policies, thus only partially reflecting the need to combat energy poverty. These states seem particularly at risk of not realizing SDG 7. Mozambique's National Energy Strategy (2014-2023) illustrates this issue. Although RE and energy efficiency are mentioned, the focus lies on diversifying the hitherto hydropower-dependent energy mix through the exploitation of recently discovered gas and coal resources. Here, the main objective is the recovery of Mozambique's position as a regional energy exporter, whose electrification rate however only covers one quarter of the population (Mokveld \& Von Eije, 2018). While the strategy aims to reach an energy access of $50 \%$ by 2023 through the expansion of grid connections and solar appliances (IEA, 2018), the transformative potential of the current energy policy remains low given the heavy attention towards gas exploration and the negligence of off-grid systems, which are promoted largely by multilateral donor initiatives.

In contrast, quadrant (1c) refers to a small but significant group of states, which have already adopted 
far-reaching policy frameworks that foster investment in the solar sector. Though far-reaching, we find that Morocco's and Algeria's policy frameworks do not address questions of energy justice but reflect a strong market orientation that downplays the need for integrating social aspects into the policy portfolio. These countries maintain trust in the markets' trickle-down effects and foster a political economy of RE that is largely privatized.

A large group of states in quadrant (2b) share some of these features and find themselves at a crossroads between market-based and justice-oriented solutions, aiming at a co-beneficial combination of both. De-risking programmes in Uganda, Zambia, Namibia, Ghana, or Ethiopia give an example of how market-creating policies labelled as 'cornerstone policies' foster deregulation of energy markets (Haag \& Müller, 2019; Waissbein et al., 2013) and may leave development-oriented RE policies at the wayside. In Uganda and Zambia (Elsner et al., in press), the GETFiT programme illustrates this: In both countries, RE projects are assigned to private investors through auctions with financial regulations leaving little space for domestic competitors. This undermines industrialization and job creation efforts as well as the opportunity for technology transfer-all aspects that are necessities for a substantial integration of RE into a nation's energy mix. Furthermore, unclear property rights may lead to the assignment of land to RE projects against the will of local farmers. However, expansion of energy access remains a pressing issue in both countries, reflected in the Zambia Vision 2030 to increase electricity access to $51 \%$ (currently $31 \%$ ) by 2030 , and the Energy for Rural Transformation III project in Uganda. Nevertheless, both countries currently lack an energy master plan for putting renewables at the forefront. With both countries increasing efforts to develop such plans, the picture here may shift shades in the future. In this regard, we get a mixed picture on both the transformative potential and the normative quality of the transition dynamics in those countries.

Finally, quadrant (1b) refers to a group of states which already have a comprehensive RE policy framework but lack the energy justice effort present in South Africa, Rwanda, and Mauritius. Tanzania provides an illustrative case in this regard, with an outstanding effort in the promotion of renewables and a fast-growing solar sector. Energy access and energy diversification are pressing issues, with a grid access rate covering $78 \%$ of the population and an energy mix based on large hydropower, gas, and coal. Tanzania deals with these challenges by applying a mix of direct, enabling, and integrative policies. Direct policies cover VAT exemptions and scaling-up RE programmes, while integrative policies include research and development and energy access programmes. Finally, enabling policies such as RE targets set clear signals to independent power producers and financers. Several policies pay respect to distributive and recognitional justice by addressing energy poverty, rural access to energy, gender-sensitive education and training on energy issues. Still, the lack of a comprehensive policy framework means that the policy interplay is not yet well balanced (AFRO_ENERGYPOL, 2020; Energypedia, 2020).

Lastly, two quadrants remain empty. Given that only states with at least a few direct RE policies were included in our sample, it is evident that we were not able to identify a fossil-based energy regime that would correspond to energy justice criteria. Equally, we could not find a country case with modest transformative quality but high energy justice concerns.

\section{Energy Transition Scenarios: Role Models and Transition Dynamics}

Overall, our matrix yields a diverse snapshot of the transition dynamics we find amongst African countries progressing towards a RE policy regime. Several countries demonstrated how comprehensive RE policy frameworks address distributive and recognitional energy justice. Mauritius, Rwanda, and South Africa are three countries cases which seem very diverse. Yet, they share the common denominator, that their energy policies are geared towards a far-reaching energy transition, whilst simultaneously contributing to greater energy justice. For realizing SDG 7 specifically, their concern for distributional and recognitional justice seems crucial. Relating their progress to SDG 7 indicators gives some evidence of how their policy goals match with SDG 7 (United Nations, 2020b). This also reveals ambivalences and inconsistencies associated with the way in which the SDG progress tracking works. SDG indicator 7.1.1 'access to electricity' shows that South Africa (84\%) and Mauritius (98\%) score high, whereas the access rate in Rwanda (29\%) is much lower. However, the change over time reveals an exponential growth in energy access also in Rwanda. SDG indicator 7.2.1, 'renewable energy,' is benchmarked in a particularly misleading way, as it does not differentiate between traditional use of biofuels and modern clean energy. This means that countries such as the Democratic Republic of the Congo score high, despite problematic practices such as artisanal charcoal production. Also, a lag in data results in low RE figures for South Africa, despite a rapid rise in RE due to the REI4P auction instrument that has already added $6.3 \mathrm{GW}$ of RE to the national grid (Baker, 2015; Müller \& Claar, in press). In terms of energy governance, all three countries maintain a high level of policy ownership, though this ownership is intermediated by strong stakeholder arrangements that align governments, donors, public, and transnational actors (AFRO_ENERGYPOL, 2020). In these cases, political interventions support the rise of RE production through market means, as visible in the proliferation of auction instruments and green funds. Still, the support of justice-related policies is reflected in the aim to combat energy poverty and to increase energy access for broad parts of the population, especially in 
rural areas. Donors contribute to these processes with capital and political expertise, thereby facilitating market entry for independent power producers and green investment. This results in an alignment of state, donor, and private sector activities.

Besides labelling these countries as positive examples, the high variability of African transition regimes and, equivocally, the broad variance in SDG implementation suggests that a scenario-based approach would allow for more leeway in terms of adequate transition governance and possible support by regional organizations and development partners. Based on our sample, we distinguish between four transition scenarios, which differ in relation to state capacities, role of development and regional partners, and political strategies.

The first scenario 'fostering transition dynamics' are captured in (1a), our three positive examples. For them, it seems necessary to further solidify their productive course towards greening their energy mixes and combatting energy poverty. This refers for instance to tapping synergies between SDG 7 and SDG 8, i.e., green industrial policies that unlock the potential of domestic $R E$ transitions in creating green jobs. This is all the more important, as the danger of a 'jobless growth' looms in any transition that heavily relies on private actors and FDI. The connection between energy justice and possible economic co-benefits, thus, needs to be addressed, e.g., by considering social investments of Independent Power Producers, community ownership and a just transition rationale (IASS, UfU, IET, \& CSIR, 2020). Also, to ensure that their green transitions remain on a stable course, these countries need to tackle the policy/implementation gap with regard to energy access and population growth, energy education, and technology transfer. While a new 'green geopolitics' is forming along the RE technology chain and its new resource needs, new path dependencies need to be systemically considered in light of African import substitution potentials.

The second scenario, 'governing transition dynamics,' refers to those states, which are progressing towards a clean energy transition, yet need to integrate justice issues more thoroughly (1b) and (2b), or, at the very least, develop more comprehensive policy frameworks (2b). Several of them, such as Ghana, Zambia, Kenya, or Namibia have made good progress in implementing SDG 7. They opened up to independent power producers and have attracted large amounts of green funds or even initiated their own green funds. However, several states in this group find themselves at a crossroads of market-oriented policies and state interventions. Zambia and Uganda's policy mixes strongly indicated this predicament (AFRO_ENERGYPOL, 2020). To resolve this and to create a mutually conducive policy mix, assessing the co-benefits of justice-related energy policies may again be a fruitful endeavour to both better understand the political economy of RE and the crosscutting nature of renewables also for realizing developmental goals. As energy poverty still is a major issue in these countries, justice-related policies should specifically tackle trade-offs between SDG 7 and SDG 8. This also underscores the need to clearly define the use of renewables within the respective political economy, that is, a differentiation between energy for development, productive use, and economic opportunity. Consequently, policy learning from the three role models and their transformation processes should be encouraged. Support through IRENA's Renewables Readiness Assessments and the Sustainable Energy for All Project (SE4AII) would also seem promising to foster policy change and address the policy/implementation gap.

The third scenario, 'putting justice into green economy,' addresses quadrant (1c) and refers to states whose energy transition heavily relies on market forces but does not pay sufficient attention to the justice dimension. In those states, the understanding of what a transition implies is mostly limited to the mere greening of a nation's energy mix. Simultaneously, the political dimension associated with every energy transition is downplayed. Accordingly, in states such as Algeria or Morocco, the current course of transition and the norms that inform the process are inherently subject to political debate. Interventions by development partners should focus on discursive interventions and generally emphasize the need to integrate the justice dimension. This can be achieved by highlighting its co-benefits, especially in relation to SDG 8 and SDG 13. Also, the involvement of civil society organisations and trade unions may open new opportunities to promote the need for a 'just transition.' This may take the form of transition scenarios that highlight co-benefits of energy justice by drawing on green industrial policies and promoting job creation in the RE sector. On a more normative level this means ensuring that whatever happens at the 'energy/development nexus' (Müller, 2017, p. 306) still is in line with genuine developmental norms and the normative concepts associated with SDG 7. This requires a shift from understanding RE as a new technology to understanding RE as a cross-cutting issue with the potential to foster far-reaching societal change (World Future Council, 2013).

Lastly, the fourth and final scenario, 'supporting newcomers to RE,' targets those countries, whose RE transitions are still in an early stage: (2c), (3b) and (3c). This category also applies to countries like Sudan or Niger, which were not even included in our sample due to a lack of RE policies in the first place. Here, we detect an alarming and widening gap between developing/lower middle-income countries and least developed/low-income countries, whose energy situation has even worsened (The World Bank Group, 2020, p. 21). The failure to cover clean cooking within the SDG implementation is a particularly pressing issue in these countries, even more so given its significant gender relevance. Here, justice-related energy policies should reflect the connection between SDG 7 and SDG 3 on health (Nilsson et al., 2018). Regarding rural access to 
$\mathrm{RE}$, the rise of rural energy funds, off-grid solutions, and solar home system as in the Zambian case (Elsner et al., in press), as well as in the examples from Tanzania or Uganda may present a viable option to address peripheral energy poverty. However, careful risk mitigation needs to be put in place to ensure that these countries can access green finance (Elsner et al., in press; The World Bank Group, 2020, p. 32).

\section{Conclusion}

Overall, our meta-analysis demonstrates that Africa's energy transition dynamics have resulted in several $R E$ policy frameworks that consider the justice dimension. They may serve as role models due to their effective combination of market-oriented policies and state interventions into the political economy of energy. The four transition scenarios further underscore the (co-)benefits of justice related RE policies at different stages of a green transition process, such as job creation, technology and knowledge transfer, and educational opportunities. In accordance with debates on SDG synergies and the need for more holistic understandings of energy transitions, we were able to give examples for policy frameworks that may contribute to 'energy wellbeing' (Samarakoon, 2019). We, also, pointed out the dangers of solely relying on market solutions. In a wider sense, our analysis underscores that justice-related RE policies can make a difference for realizing the goals of SDG 7, both, at a higher level of policy ownership and in a way that better corresponds to people's energy needs and vulnerabilities. Justice-related RE policies will allow for the creation of a policy framework that pays attention to the social change rationale, which forms the basis of SDG 7, yet is oftentimes addressed rather implicitly. In essence, we emphasize the need to adjust SDG 7's tracking procedures by also assessing the effects of promising policies instead of merely relying on single indicators.

\section{Acknowledgments}

We thank the Academic Editors and the two anonymous reviewers for their very constructive critique. For formatting and proofreading we owe a thank you to Nele Brebeck, Ellie Gunesch and Nomaswazi Mthombeni. Research for this article was publicly financed through two grants issued by the German Federal Ministry of Education and Research (grant numbers: 01LN1207A and 01LN1207B).

\section{Conflict of Interests}

The authors declare no conflict of interests.

\section{Supplementary Material}

Supplementary material for this article is available online in the format provided by the author. Please refer to this supplementary file via this link: http://dx.doi.org/ $10.17632 / \mathrm{m} 7 \mathrm{fkgsbtf6.1}$

\section{References}

AFRO_ENERGYPOL. (2020). AFRO_ENERGYPOL database of African renewable energy policies. Mendeley Data. Retrieved from https://data.mendeley.com/ datasets/grhystdwdr/1

Baker, L. (2015). The evolving role of finance in South Africa's renewable energy sector. Geoforum, 64, 146-156.

Barthel, B. (2019). Erneuerbare und dezentrale Energien aus postkolonialer Perspektive [Renewable and decentralized energies from a postcolonial perspective]. Baden-Baden: Nomos.

Boamah, F., \& Rothfuß, E. (2018). From technical innovations towards social practices and socio-technical transition? Re-thinking the transition to decentralised solar PV electrification in Africa. Energy Research \& Social Science, 42, 1-10.

Brato, V. C., Baptista, I., Kirshner, J., Smith, S., \& Alves, S. N. (2018). Energy justice and sustainability transitions in Mozambique. Applied Energy, 228, 645-655.

Bullard, R. D. (2005). The quest for environmental justice: Human rights and the politics of pollution. San Francisco, CA: Sierra Club Books.

Bullard, R. D., Johnson, G. S., \& Wright, B. H. (1997). Confronting environmental injustice: It's the right thing to do. Race Gender and Class, 5(1), 63-79.

Calzadilla, P. V., \& Mauger, R. (2017). The UN's new sustainable development agenda and renewable energy: The challenge to reach SDG 7 while achieving energy justice. Journal of Energy \& Natural Resources Law, 36(2), 233-225.

Claar, S. (2020). Green finance and transnational capitalist classes: Tracing vested capital interests in renewable energy investment in South Africa. Journal für Entwicklungspolitik, 37, 110-128.

Climate Policy Initiative. (2019). Global landscape of climate finance 2019, London: Climate Policy Initiative. Retrieved from https://climatepolicyinitiative. org/publication/global-climate-fnance-2019

Elsner, C., Neumann, M., Müller, F., \& Claar, S. (in press). Room for money or manoeuvre? How green financialization and de-risking shape Zambia's renewable energy transition. Kassel: University of Kassel.

Energypedia. (2020). Tanzania energy situation. Energypedia. Retrieved from https://energypedia.info/ wiki/Tanzania_Energy_Situation

Fischer, F., \& Forester, J. (1993). The argumentative turn in policy analysis and planning. Durham, NC and London: Duke University Press.

Frankfurt School of Finance. (2017). Global trends in renewable energy investments. Frankfurt: Frankfurt School of Finance.

Fraser, N. (1999). Social justice in the age of identity politics. In G. Henderson (Ed.), Geographical thought: A 
praxis perspective (pp. 56-89). London: Taylor and Francis.

Gabor, D. (2019). Securitization for sustainability: Does it help achieve the Sustainable Development Goals? Washington, DC: Heinrich Böll Stiftung.

Gabor, D. (2020). The Wall Street consensus. SocArxiv. https://doi.org/10.31235/osf.io/wab8m

Geels, F. W. (2002). Technological transitions as evolutionary reconfiguration processes: A multi-level perspective and a case-study. Research Policy, 31(8/9), 1257-1274.

Gellers, J. C., \& Cheatham, T. J. (2019). Sustainable Development Goals and environmental justice: Realization through disaggregation? Wisconsin International Law Journal, 36(2), 276-297.

Global-Climatescope. (2017). Database of climate and energy policies. Global-Climatescope. Retrieved from http://global-climatescope.org/en/policies/\#

Haag, S., \& Müller, F. (2019). Finanzplatz Afrika: Grüne Finanzflüsse und afrikanische Energietransitionen [Financial hub Africa: Green finance flows and african energy transitions]. In H. Melber (Ed.), Deutschland und Afrika: Anatomie eines komplexen Verhältnisses [Germany and Africa: Anatomy of a complex relationship] (pp. 55-70). Frankfurt: Brandes \& Aspel.

Hajer, M., \& Veersteg, W. (2005). Performing governance through networks. European Political Science, 4, 340-347.

Hajer, M., \& Wagenaar, H. (Eds.). (2003). Deliberative policy analysis: Understanding governance in the network society. Cambridge: Cambridge University Press.

Heffron, R. J., \& McCauley, D. (2017). The concept of energy justice across the disciplines. Energy Policy, 105, 658-667.

Hermans, L. M. (2008). Exploring the promise of actor analysis for environmental policy analysis: Lessons from four cases in water resources management. Ecology and Society, 13(1). http://www. ecologyandsociety.org/vol13/iss1/art21

IASS, UfU, IET, \& CSIR. (2020). Making the Paris Agreement a success for the planet and the people of South Africa. Potsdam and Pretoria: COBENEFITS.

IEA. (2018). Mozambique. IEA. Retrieved from https:// www.iea.org/countries/mozambique

IEA, \& IRENA. (2018). Joint policies and measures database. IEA. Retrieved from https://www.iea.org/ policiesandmeasures/renewableenergy

IRENA, IEA, \& REN21. (2018). Renewable energy policies in a time of transition. Abu Dhabi: IRENA. Retrieved from https://www.irena.org/-/media/Files/IRENA/ Agency/Publication/2018/Apr/IRENA_IEA_REN21_ Policies_2018.pdf

Jenkins, K., McCauley, D., Heffron, R., Stephan, H., \& Rehner, R. (2016). Energy justice: A conceptual review. Energy Research \& Social Science, 11, 174-182.

Kern, F., \& Markard, J. (2016). Analysing energy transitions: Combining insights from transition studies and international political economy. In T. Van de Graaf, B. K. Sovacool, A. Ghosh, F. Kern, \& M. T. Klare (Eds.), The Palgrave handbook of the international political economy of energy (pp. 291-318). London: Palgrave Macmillan.

Kroll, C., Warchold, A., \& Pradhan, P. (2019). Sustainable Development Goals (SDGs): Are we successful in turning trade-offs into synergies? Palgrave Communications, 5. https://doi.org/10.1057/s41599-0190335-5

Lacey-Barnacle, M., Robison, R., \& Foulds, C. (2020). Energy justice in the developing world: A review of theoretical frameworks, key research themes and policy implications. Energy for Sustainable Development, 55, 122-138.

Lepennies, P. (2015). Modeling, statistics, and circumstance: How the concept of economic development triumphed and what this means for development alternatives. European Journal of Sociology, 56(3), 375-404.

Loomis, J., \& Helfand, G. (2001). Environmental policy analysis for decision making. Amsterdam: Springer.

Ministry of Infrastructure of Republic of Rwanda. (2009). National energy policy and national energy strategy 2008-2012. Kigali: Ministry of Infrastructure of Republic of Rwanda. Retrieved from http://www.euei-pdf.org/sites/default/files/field_ publication_file/EUEI_PDF_Rwanda_Energy_Policy_ 2008-2012_Final_Jan_2009_EN.pdf

Mokveld, K., \& Von Eije, S. (2018). Final energy report Mozambique. Amsterdam: Ministry of Foreign Affairs. Retrieved from https://www.rvo.nl/ sites/default/files/2019/01/Final-Energy-reportMozambique.pdf

Müller, F. (2017). IRENA as a glocal actor: Pathways towards energy governmentality. Innovation, 30(3), 306-322.

Müller, F., \& Claar, S. (in press). Auctioning a 'just energy transition'? South Africa's renewable energy procurement programme and its implications for transition strategies. Review of African Political Economy.

Müller, F., Claar, S., Neumann, M., \& Elsner, C. (2020). Is green a pan-African colour? Mapping African renewable energy policies and transitions in 34 countries. Energy Research and Social Science, 68. https://doi. org/10.1016/j.erss.2020.101551

Newell, D., \& Mulvaney, H. (2013). The political economy of the 'just transition.' The Geographical Journal, 172(2), 132-140.

Nilsson, M., Chisholm, E., Griggs, D., Howden-Chapman, P., McCollum, D., Neumann, B., ... Stafford-Smith, M. (2018). Mapping interactions between the sustainable development goals: Lessons learned and ways forward. Sustainability Science, 13, 1489-1503.

Otieno, D., Taylor, H., Schroth, D., \& Franz, M. (2016). Mapping of energy initiatives and programs in Africa: Final report. Eschborn: European Union Energy Initiative Partnership Dialogue Facility. 
Quitzow, R., Roehrkasten, S., Jacobs, D., Bayer, B., Jamea, E. M., Waweru, Y., \& Matschoss, P. (2016). The future of Africa's energy supply. Potsdam: IASS.

Rawls, J. (1991). A theory of justice. Cambridge: Cambridge University Press. (Original work published 1971)

REN 21. (2018). Renewables global status report. Paris: REN 21. Retrieved from https://www.ren21.net/wpcontent/uploads/2019/08/Full-Report-2018.pdf

REN 21. (2020). Renewables global status report. Paris: REN 21. Retrieved from https://www.ren21.net/wpcontent/uploads/2019/05/gsr_2020_full_report_ en.pdf

Republic of Mauritius. (2009). Long-term energy strategy 2009-2025. Port Louis: Ministry of Energy and Public Utilities. Retrieved from https:// sustainabledevelopment.un.org/content/ documents/1245mauritiusEnergy\%20Strategy.pdf

Rogge, K. S., \& Reichardt, K. (2016). Policy mixes for sustainability transitions: An extended concept and framework for analysis. Research Policy, 45, 1620-1635.

Samarakoon, S. (2019). A justice and wellbeing centered framework for analysing energy poverty in the Global South. Ecological Economics, 165. https://doi.org/ 10.1016/j.ecolecon.2019.106385

Sen, A. (2009). The idea of justice. Cambridge, MA: Allen Lane and Harvard University Press.

Sovacool, B. K. (2016). How long will it take? Conceptualizing the temporal dynamics of energy transitions. Energy Research \& Social Science, 13, 202-215.

Sovacool, B. K., Burke, M., Baker, L., Kotikalapudi, C. K., \& Wlokas, H. (2017). New frontiers and conceptual frameworks for energy justice. Energy Policy, 105, 677-691.

Sovacool, B. K., \& Dworkin, M. H. (2015). Energy justice: Conceptual insights and practical applications. Applied Energy, 142, 435-444.

Swilling, M., \& Annecke, E. (2012). Just transitions: Explorations of sustainability in an unfair world. New York, NY: United Nations University Press.
Tarekegne, B. (2020). Just electrification: Imagining the justice dimensions of energy access and addressing energy poverty. Energy Research \& Social Science, 70. https://doi.org/10.1016/j.erss.2020.101639

The World Bank Group. (2017). Regulatory indicators for sustainable energy (RISE) (2017). The World Bank Group. Retrieved from http://rise.esmap.org

The World Bank Group. (2020). Tracking SDG 7: The energy progress report. Washington, DC: World Bank. Retrieved from https://trackingSDG7.esmap.org/ data/files/download-documents/01-SDG7executivesummary_0.pdf

United Nations. (2020a). Progress towards the Sustainable Development Goals: Report of the SecretaryGeneral. New York, NY: United Nations. Retrieved from https://unstats.un.org/sdgs/files/report/2020/ secretary-general-sdg-report-2020-V-EN.pdf

United Nations. (2020b). SDG tracker. United Nations. Retrieved from https://sdg-tracker.org/energy

Waissbein, O., Glemarec, Y., Bayraktar, H., \& Schmidt, T. S. (2013). Derisking renewable energy investment: A framework to support policymakers in selecting public instruments to promote renewable energy investment in developing countries. New York, NY: United Nations Development Programme. Retrieved from https://www.undp.org/content/ dam/undp/library/Environment\%20and\%20Energy/ Climate\%20Strategies/UNDP\%20Derisking\% 20Renewable\%20Energy\%20Investment\%20\%20Full\%20Report\%20(April\%202013).pdf

Weible, C. M., \& Sabatier, P. A. (2005). Comparing policy networks: Marine protected areas in California. Policy Studies Journal, 33(2), 181-201.

World Future Council. (2013). Powering Africa through feed-in tariffs. Hamburg: World Future Council. Retrieved from https://ke.boell.org/sites/default/ files/2013-03-powering-africa_through-feed-intariffs.pdf

Ziai, A. (2015). Development discourse and global history. London: Routledge.

\section{About the Authors}

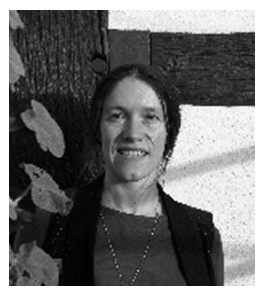

Franziska Müller is Assistant Professor for Globalization and Climate Governance and leads the research group "GLOCALPOWER: Funds, tools, and networks for an African energy transition" at the University of Hamburg. Her main research interests are global climate and energy governance as well as theories of international relations. Her current research focuses on international politics in the Anthropocene, green financialization, and transformations of postcolonial statehood.

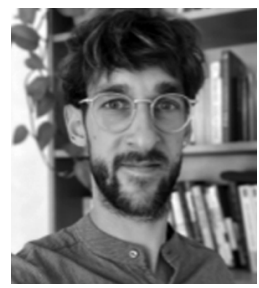

Manuel Neumann is a Research Fellow of the research group "Glocalpower" anchored in the Department of Political Science. He holds a Master's degree in Globalisation and Development from SOAS (University of London). Previously, he read Political Science at Delhi University and completed a Bachelor's degree in International Economics from Tübingen University. His research revolves around the political economy of energy transitions in developing and emerging economies more generally and green financial tools such as green bonds in particular. 

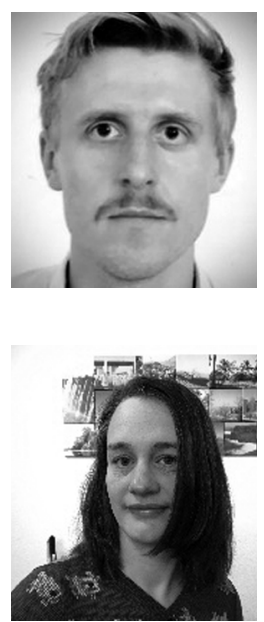

Carsten Elsner is a Research Associate in the research group "Glocalpower" based at the Political Science Department at the University of Kassel. He holds a Master's degree in Political Economy of Development from the School of Oriental and African Studies (SOAS), University of London. Previously he completed a Bachelor of Arts in Political Science and a Bachelor of Science in Economics at the Ludwig-Maximilians-Universität in Munich (LMU). His current research revolves around the political economy of energy transitions in Africa and standardisation processes of green finance with a focus on the EU taxonomy.

Simone Claar leads the research group "Glocalpower: Funds, tools, and networks for an African energy transition" at the University of Kassel. Her research interests include international political economy focusing on trade policy, capitalism in Africa, and renewable energies. The regional focus lies on emerging markets and Sub-Sahara Africa. Currently, she investigates the involvement of trade unions in renewable energy transitions and the emergence of a 'Green Capitalism in Africa.' 